\title{
ANTAGONISTIC EFFECTS OF THREE LACTIC ACID BACTERIAL STRAINS ISOLATED FROM NIGERIAN INDIGENOUS FERMENTED OGI ON E. COLI EKTO04 IN CO-CULTURE
}

\author{
A.O. Afolayan and F.A. Ayeni* \\ Department of Pharmaceutical Microbiology, Faculty of Pharmacy, University of Ibadan, Postcode: 200284, \\ Ibadan. Nigeria
}

(Received: 29 January 2016; accepted: 6 May 2016)

E. coli is one of the major pathogenic bacteria that cause diarrhoea in human. Traditional fermented foods, e.g. Ogi, has been used indigenously to treat diarrhoea. This study was aimed at investigating the antagonistic activity of selected lactic acid bacteria (LAB) isolated from three varieties of ogi against multidrug resistant E. coli EKT004. Antibiotic susceptibility of the tested E. coli EKT004 strain to ofloxacin, gentamycin, cefuroxime, ceftazidine, lincomycin, oxacillin, cloxacillin, cefotaxime, ciprofloxacin, and nitrofurantoin was tested by disc diffusion method. E. coli EKT004 was co-incubated in two different experiments with Weissella paramesenteroides, Lactobacillus plantarum, and L. fermentum that have been previously isolated from Ogi. An 8 h old E. coli was introduced into an overnight culture of LAB and a fresh $E$. coli was inoculated into overnight culture of LAB. Viable count of pathogen at $0 \mathrm{~h}$ and after $24 \mathrm{~h}$ co-incubation at $37^{\circ} \mathrm{C}$ was observed.

The tested E. coli EKT004 was resistant to cefuroxime, ceftazidime, lincomycin, oxacillin, cloxacillin, and cefotaxime. The tested LAB isolates have a broad spectrum of activity against $E$. coli EKT004 used for the study with a decrease of 6-8 $\log$ of $E$. coli as compared with the control. These results indicate a direct effect of lactic acid bacterial strains on multidrug resistant $E$. coli strain.

Keywords: co-culture, lactic acid bacteria, diarrhoea, resistance

Most gastrointestinal tract diseases caused by bacterial pathogens or their toxins are spread through food or water. Transmission follows the faecal-oral route where contaminated food or water represents the vehicle for transmission. E. coli is one of the organisms most frequently isolated from different clinical cases of diarrhoea (OKеке et al., 1999; Товін et al., 2006). Diarrhoea, which is an illness characterized by an increase in frequency and fluidity of stools is one of the most common diseases causing infant death in developing countries (Cheesbrough, 1994; Walderman, 1998). Diarrheal diseases continue to be a major cause of morbidity and mortality worldwide. The cornerstone of treatment recommended by the World Health Organization (WHO) remains the use of oral rehydration solution (ORS). As emphasized by GUANDALINI (2002), despite dramatic progresses in the understanding of the pathophysiology of diarrhoea, the list of drugs available is indeed short. The administration of antimicrobial agents, therapeutically or prophylactically, causes disturbances in the ecological balance between the host and the normal microbiota, leading to intestinal colonization by potentially pathogenic microorganisms and overgrowth by opportunistic microorganisms already present, followed by diarrhoea and fungal infections (SULLIVAN et al., 2001).

\footnotetext{
* To whom correspondence should be addressed. Phone: +234 7036138816; e-mail: fa.ayeni@ui.edu.ng
} 
Furthermore, antimicrobial resistance has become a serious public health problem worldwide. Infections caused by resistant bacteria have been shown to be more frequently associated with increased morbidity and mortality than those caused by susceptible pathogens (Helms et al., 2002; Travers \& BARZA, 2002). Some studies have already shown that $E$. coli often resist antibiotics such as ampicillin, amoxicillin-clavulanic acid, cotrimoxazole, nalidixic acid, and cephalothin (AlshARA, 2011). Several factors result in increasing antimicrobial drug resistance rates in poor countries such as irrational antimicrobial drug usage and conditions of poor sanitation (OKEKE et al., 1999; BARTOLONI et al., 2006; TOBIH et al., 2006).

The addition of a medication to the WHO protocol for the treatment of acute diarrhoea in children is controversial. Recently, in addition to ORS, several new therapeutic strategies, including selected Lactobacillus strains and biotherapeutic agents containing selected, heatkilled Lactobacillus strains, have demonstrated considerable potential for promoting a more rapid recovery from acute, watery diarrhoea by children with microbial enteritis (IsOLAURI et al., 2002).

Ogi is an acid fermented cereal gruel or porridge made from maize (Zea mays) or corn: sorghum (Sorghum vulgare) also known as guinea corn or millet (Pennisetum americanum) (OHENHEN \& IKENEBOMEH, 2007). It is the most popular traditional health-sustaining fermented food in Western Nigeria, and serves as weaning foods for infants. In some communities in south-western Nigeria, Ogi is normally administered to people having gastroenteritis to minimize discomforts (ADERIYE \& LALEYE, 2003; DAVID \& FAMUREWA, 2010). Lactic acid bacteria have been directly involved in the fermentation of Ogi, but only minimal studies have shown their antimicrobial potential against gastrointestinal pathogens. Therefore, this study was carried out to evaluate the ability of LAB isolated from Ogi to prevent the growth of $E$. coli strain in co-culture.

\section{Materials and methods}

\subsection{Microorganisms}

Lactic acid bacterial strains have been previously isolated from Ogi, a Nigerian fermented cereal gruel, and identified by partial sequencing of the 16S rRNA gene. Three of the identified LAB strains were selected for co-culture studies based on their efficient antagonistic properties. They are: Weissella paramesenteroides AFN004, Lactobacillus fermentum AFN018, and L. plantarum AFN021. Clinical strain of E. coli EKT004 isolated from gastrointestinal tract was collected from Medical Microbiology unit, Ekiti State University Teaching Hospital, Ado-Ekiti, Ekiti State Nigeria.

\subsection{Antibiotic susceptibility of E. coli EKT004}

The susceptibility of E. coli EKT004 to various antibiotics was tested by disc diffusion method. The antibiotics used were ofloxacin $(30 \mu \mathrm{g})$, cefuroxime $(30 \mu \mathrm{g})$, ceftazidine $(30$ $\mu \mathrm{g})$, lincomycin $(30 \mu \mathrm{g})$, oxacillin $(10 \mu \mathrm{g})$, cloxacillin $(10 \mu \mathrm{g})$, augmentin $(10 \mathrm{mg})$, cefotaxime (30 $\mu \mathrm{g})$, ciprofloxacin $(30 \mu \mathrm{g})$, nitrofurantoin $(100 \mu \mathrm{g})$, and gentamicin $(30 \mu \mathrm{g})$. The susceptibility of the test organism to the used antibiotics was evident by clear zones of inhibition around the antibiotics disks, and the results were interpreted according to the guidelines of European Committee on Antimicrobial Susceptibility Testing (EUCAST, 2015). 


\subsection{Co-culture of lactic acid bacteria and $\mathrm{E}$. coli}

The interference of LAB with the growth of pathogenic strains was evaluated by co-incubating Escherichia coli EKT004 individually with three representative strains of LAB (Weissella paramesenteroides AFN004, L. fermentum AFN018, L. plantarum AFN021) according to the modified method of Drago and co-workers (1997). This was done in two series of experiments.

In the first experiment, $1 \mathrm{ml}$ of $E$. coli EKT004 corresponding to $2.96 \times 10^{11} \mathrm{CFU} \mathrm{m}^{-1}$ was inoculated into $5 \mathrm{ml}$ double strength nutrient broth, and then added to $5 \mathrm{ml}$ of overnight culture of LAB and incubated for $24 \mathrm{~h}$ at $37^{\circ} \mathrm{C}$. The monoculture of the LAB and E. coli was evaluated at time zero $\left(\mathrm{t}_{0}\right)$ by plating from an appropriate dilution factor onto MRS agar and MacConkey agar, respectively, followed by incubation at $37{ }^{\circ} \mathrm{C}$ for $24 \mathrm{~h}$. Then, the mixture was serially diluted, and the appropriate dilution factor was plated accordingly to determine the colony counts of LAB and pathogen.

For the second experiment, both E. coli and the LAB were grown for $24 \mathrm{~h}$ at $37{ }^{\circ} \mathrm{C}$. From the overnight culture of the pathogen corresponding to $2.96 \times 10^{11} \mathrm{CFU} \mathrm{ml}^{-1} 1 \mathrm{ml}$ was inoculated into fresh nutrient broth and incubated for $8 \mathrm{~h}$ at $37{ }^{\circ} \mathrm{C}$. After that the pathogen culture was centrifuged (for $10 \mathrm{~min}$ at 10000 r.p.m.) and the supernatant discarded, then $5 \mathrm{ml}$ of double strength nutrient broth was added to resuspend the pellet, vortexed, and added to 5 $\mathrm{ml}$ of overnight culture of LAB making the whole mixture $10 \mathrm{ml}$. Serial dilution of both the pathogen alone (monoculture) and the mixture (co-culture) was done at $8 \mathrm{~h}$, immediately after mixing, followed by plating out at appropriate dilutions. After $24 \mathrm{~h}$ incubation at $37^{\circ} \mathrm{C}$, appropriate serial dilutions of the mixture (co-culture) were plated on their respective selective media. Discrete colonies were counted and recorded.

\section{Results and discussion}

The menace of antibiotic resistance is a worldwide threat with accompanied therapeutic failure. This study reports the resistance of tested $E$. coli strain to $60 \%$ of tested antibiotics. The pathogen was resistant to lincomycin, oxacillin, cloxacillin, and ceftazidine. DeNVER (2004) reported that amoxicillin and cloxacillin have no significant activity against Gramnegative pathogens and Pseudomonas aeruginosa. The test pathogen was also resistant to cefuroxime. Previous studies (Osterblad et al., 1999; ReDa et al., 2011) have shown that some pathogenic isolates from the Enterobacteriaceae family (Salmonella spp., Shigella spp., and E. coli) are resistant to cefuroxime, ampicillin, and amoxycillin/clavulanate. These results suggest that lincomycin, oxacillin, cloxacillin, ceftazidine, and cefuroxime should not be used in treating infections caused by pathogenic E. coli and other related diarrhoeagenic pathogens, as these pathogens have developed resistance to these antibiotics. The tested strain was sensitive to ofloxacin, gentamycin, ciprofloxacin, and nitrofurantoin. This result is in agreement with OSTERBLAD and co-workers (1999) and YISMAW and co-workers (2006), whose pathogenic isolates exhibited the least resistance to the above-named antibiotics.

In the present study we have shown that $W$. paramesenteroides AFN004, L. fermentum AFN018, and L. plantarum AFN021, which have been previously isolated from uncooked white Ogi ( $W$. paramesenteroides AFN004, L. plantarum AFN021) and sorghum Ogi ( $L$. fermentum AFN018), effectively inhibited the growth of E. coli EKT004, either when inoculated after $8 \mathrm{~h}$ and $24 \mathrm{~h}$ of growth of pathogen or when cultured overnight and then 
incubated with the pathogens. In contrast, the growth of the LAB was not significantly influenced by the presence of the pathogen (Figs 1-3).

Co-culture studies of overnight culture of $W$. paramesenteroides isolated from uncooked white Ogi showed that this LAB has a broad spectrum of activity against $E$. coli used for the study with a decrease of 6-8 $\log$ of the pathogen as compared with the control (Fig. 1). Previous studies (PAL \& RAMANA, 2010) revealed that the purified bacteriocin from $W$. paramesenteroides isolated from cucumber exhibited a broad inhibitory spectrum against foodborne pathogens and spoilage microorganisms, including Gram-negative bacteria such as Salmonella Typhimurium, Vibrio parahaemolyticus, Aeromonas hydrophila and Listeria monocytogenes. They also noted that in spite of various bacteriocins studied worldwide, studies on bacteriocins of Weissella paramesenteroides remain rare, hence the need to utilize the potentials of $W$. paramesenteroides isolated from Ogi as a probiotic. This study also emphasizes on the need to consume more of uncooked Ogi because of its probiotic benefits.

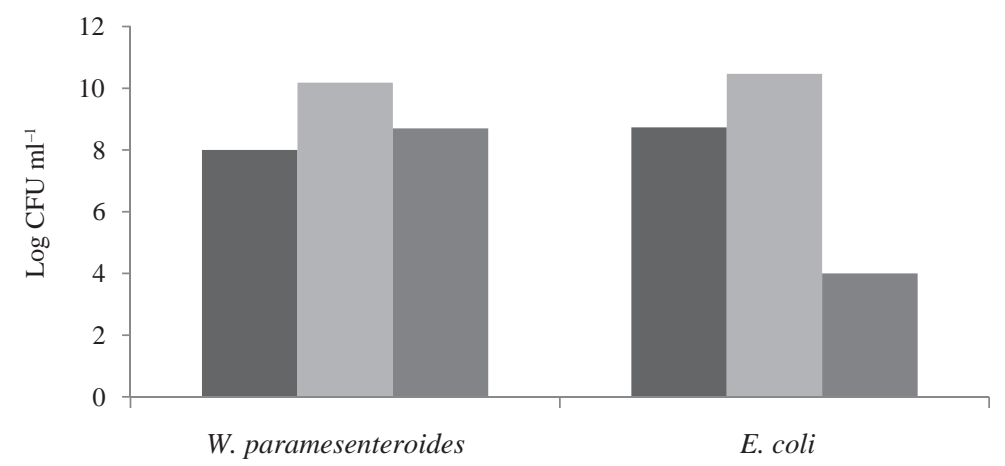

Fig. 1. Inhibition of in vitro growth of E. coli EKT004 by W. paramesenteroides AFN004 in co-culture : Control at $0 \mathrm{~h} ; \quad$ : control at $24 \mathrm{~h} ; \quad$ : co-culture at $24 \mathrm{~h}$

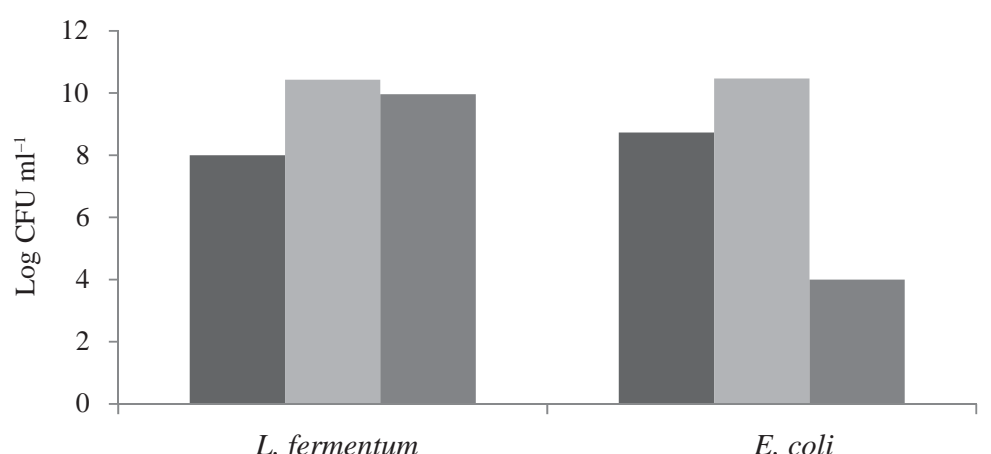

Fig. 2. Inhibition of in vitro growth of E. coli EKT004 by L. fermentum AFN018 in co-culture : Control at $0 \mathrm{~h} ; \quad$ : control at $24 \mathrm{~h} ; \quad$ : co-culture at $24 \mathrm{~h}$ 
Co-culture studies of overnight culture of $L$. fermentum revealed that this LAB reduced the concentration of the cells of multidrug resistant $E$. coli by $6 \log$ as compared to the control (Fig. 2). In the $8 \mathrm{~h}$ co-culture experiments, the concentration of $E$. coli cells decreased by 1 $\log$, while at $24 \mathrm{~h}$, the concentration of $E$. coli cells decreased by $5 \log$ as compared to the control (Figs 4-6). AlLAART and co-workers (2011) also reported that co-culturing of Clostridium perfringens with $L$. fermentum under in vitro conditions showed that, $L$. fermentum was capable of silencing beta2 toxin production of $C$. perfringens without influencing bacterial viability.

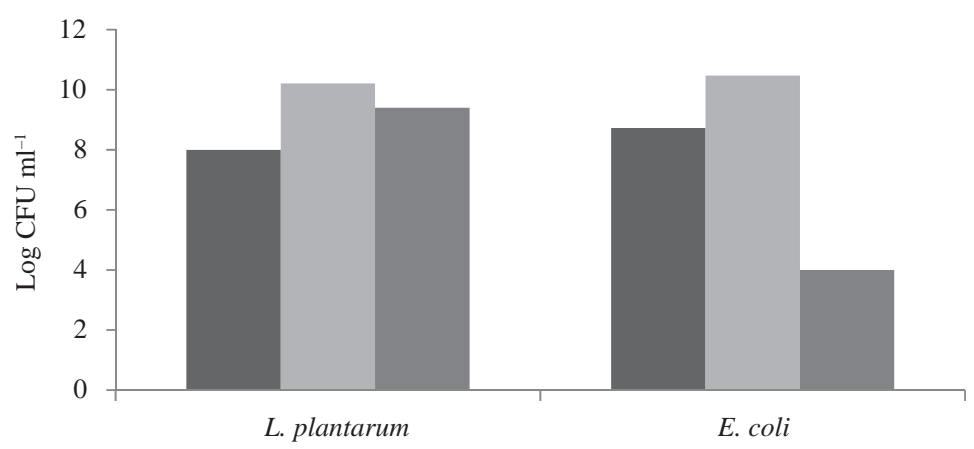

Fig. 3. Inhibition of in vitro growth of E. coli EKT004 by L. plantarum AFN021 in co-culture : Control at $0 \mathrm{~h} ; \mathrm{a}$ : control at $24 \mathrm{~h} ; \mathrm{z}$ : co-culture at $24 \mathrm{~h}$

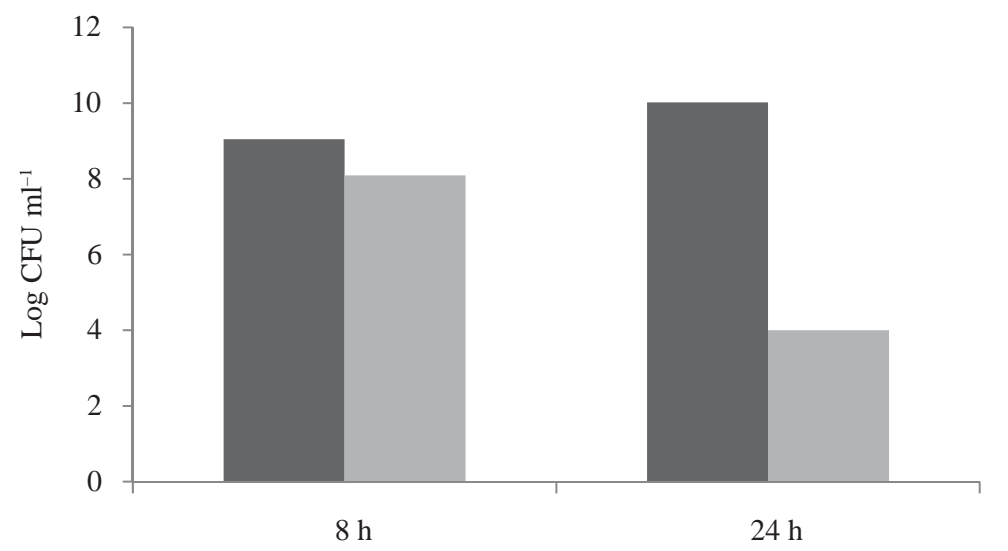

Fig. 4. Antimicrobial activities of $W$. paramesenteroides AFN004 against 8 h grown E. coli EKT004 in co-culture : Control; : : co-cultured with $W$. paramesenteroides

This co-culture study also revealed and confirmed the antagonistic activity of $L$. plantarum against $E$. coli. There was a $6 \log$ reduction of the concentration of the pathogen cells when co-cultured with a 24-h culture (Fig. 3). This study was in agreement with previous studies by SzALA and co-workers (2012), where they reported that during two-day culture of 
Salmonella Senftenberg and Lactobacillus plantarum strains No. 6 and 15 and L. brevis No. 8 , total inactivation of the pathogen was observed in all the tested mixed cultures with the largest decrease (in the count of Salmonella Senftenberg rods in mixed culture) between the $16^{\text {th }}$ and the $24^{\text {th }} \mathrm{h}$ of incubation, when the concentration of pathogen cells fell rapidly from values of $6 \log$ to no detection level.

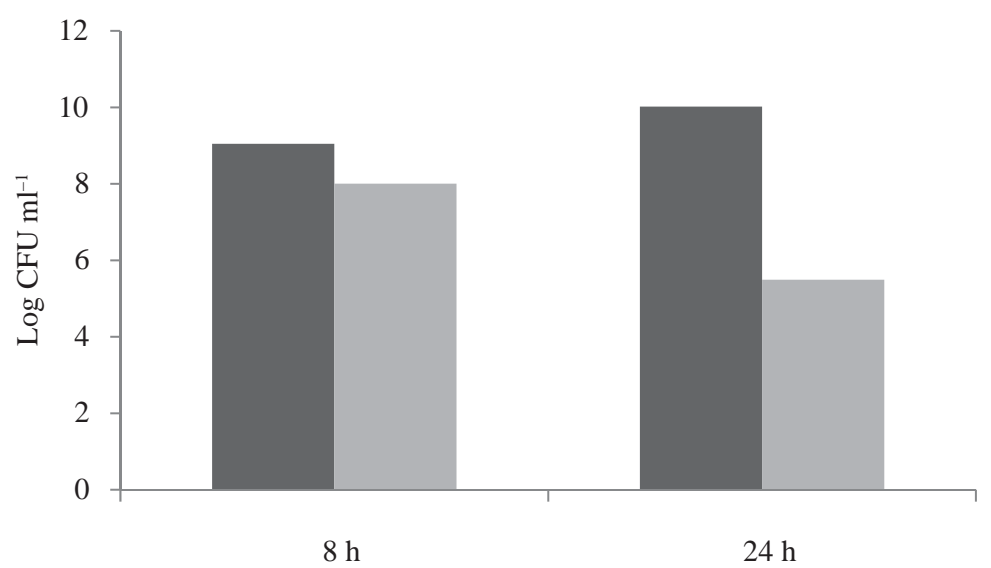

Fig. 5. Antimicrobial activities of $L$. fermentum AFN018 against 8 h grown E. coli EKT004 in co-culture : Control; : : co-cultured with L. fermentum

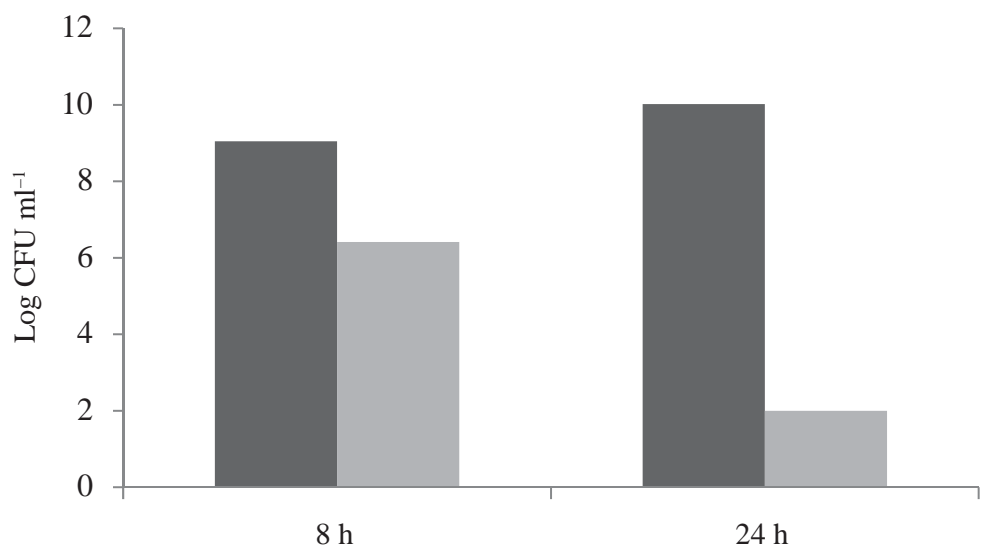

Fig. 6. Antimicrobial activities of L. plantarum AFN021 against 8 h grown E. coli EKT004 in co-culture : Control; : co-cultured with L. plantarum

In the second co-culture experiment, at $8 \mathrm{~h}$, the concentration of $E$. coli cells decreased by $3 \mathrm{log}$, while at $24 \mathrm{~h}$, the concentration of $E$. coli cells decreased by $8 \log$ as compared to the control (Figs 2, 5). AlAKOMI and co-workers (2000) reported that organic acids produced by LAB are the agents that inhibited the growth of Gram-negative bacteria such as E. coli and Salmonella sp. 


\section{Conclusions}

The presence of multidrug resistant $E$. coli strains has necessitated the search for other agents outside antibiotics that could reduce the population of the pathogen in the infectious site. This study shows that Weissella paramesenteroides, Lactobacillus plantarum, and L. fermentum naturally present in indigenous fermented Ogi reduced $E$. coli viable counts in co-culture and would have a great potential in inhibiting the growth of gastrointestinal E. coli when Ogi containing the tested LAB is consumed. This proves that the beneficial bacteria present in indigenous fermented foods have antimicrobial properties against gastrointestinal pathogens.

\section{References}

Aderiye, J.B.I. \& Laleye, S.A. (2003): Relevance of fermented food products in southwest Nigeria. Plant Food. Hum. Nutr., 58, 1-16.

Alakomi, H., Skytta, E., Saarela, M., Mattila-Sandholm, T., Latva-Kala, K. \& Helander, I. (2000): Lactic acid permeabilizes Gram-negative bacteria by disrupting the outer membrane. Appl. Environ. Microb., 66, 2001.

Allaart, J.K., van Asten, J.A.M.A., Vernoois, J.C.M. \& Grone, A. (2011): Effect of Lactobacillus fermentum on beta2 toxin production by Clostridium perfringens. Appl. Environ. Microb., 77, 4406-4411.

Alshara, M. (2011): Antimicrobial resistant pattern of Escherichia coli strains isolated from paediatric patients in Jordan. Acta Med. Iran., 49(5), 293-295.

Bartoloni, A., Bartalesi, F., Mantella, A., Dell'Amico, E., Roselli, M., Strohmeyer, M., Barahona, H.G., Barrón, V.P., Paradisi, F. \& Rossolini, G.M. (2006): High prevalence of acquired antimicrobial resistance unrelated to heavy antimicrobial consumption. J. Infect. Dis., 189(7), 1291-1294.

Cheesbrough, M. (1994): Medical laboratory manual for tropical countries. Vol. II. Microbiology. ELBS, Cambridge University Press, Great Britain. 479 pages

David, O.M. \& Famurewa, O. (2010): Prophylactic and bio-therapeutic benefits of 'ogi': A lactic acid fermented food. Researcher, 2(9), 72-77.

Denver, R.A. (2004): Types of antibiotics and synthetic antimicrobial agents. -in: DenYer, S.P., Hodges, N.A. \& Gorman, S.P. (Eds) Hugo \& Russell's pharmaceutical microbiology. Blackwell Science, Massachusetts. pp. $152-154$.

Drago, L., Gismondo, M.R., Lombardi, A., de Haen, C. \& Gozzini, L. (1997): Inhibition of in vitro growth of enteropathogens by new Lactobacillus isolates of human intestinal origin. FEMS Microbiol. Lett., 153, 455463.

EUCAST (2015): Breakpoint tables for interpretation of MICs and zone diameters. Version 5.0. European Committee on Antimicrobial Susceptibility Testing

Guandalini, S. (2002): The treatment of acute diarrhea in the third millennium: a pediatrician's perspective. Acta Gastro-ent. Belg., 65, 33-36.

Helms, M., Vastrup, P., Gerner-Smidt, P. \& Mølbak, K. (2002): Excess mortality associated with antimicrobial drug-resistant Salmonella typhimurium. Emerg. Infect. Dis., 8(5), 490-495.

Isolauri, E., Kirjavainen, P.V. \& Salminen, S. (2002): Probiotics: a role in the treatment of intestinal infection and inflammation? Gut, 50(3), 54-59.

Ohenhen, R.E. \& Ikenebomen, M.J. (2007): Shelf stability and enzyme activity studies of Ogi: A corn meal fermented product. J. Am. Sci., 3(1), 38-42.

Okeke, I.N., Lamikanra, A. \& Edelman, R. (1999): Socioeconomic and behavioral factors leading to acquired bacterial resistance to antibiotics in developing countries. Emerg. Infect. Dis., 5(1), 18-27.

Osterblad, M., Pensala, O., Peterzens, M., Heleniusc, H. \& Huovinen, P. (1999): Antimicrobial susceptibility of Enterobacteriaceae isolates from vegetables. J. Antimicrob. Chemoth., 43, 503-509.

PAL, A. \& RamAna, K.V. (2010): Purification and characterization of bacteriocin from Weissella paramesenteroides DFR-8, an isolate from cucumber (Cucumis sativus). J. Food Biochem., 34, 932-948.

Reda, A.A., Seyoum, B., Yimam, J., Andualem, G., Fiseha, S. \& Vandeweerd, J. (2011): Antibiotic susceptibility pattern of Salmonella and Shigella isolates in Harar, Eastern Ethiopia. J. Infect. Dis. Immun., 3(8), 134-139.

Sullivan, A., Edlund, C. \& Nord, C.E. (2001): Effect of antimicrobial agents on the ecological balance of human microflora. Lancet Infect. Dis. 1, 101-114. 
Szala, B., Paluszak, Z. \& Motyl, I. (2012): Antagonistic effect of lactic acid bacteria on Salmonella Senftenberg in mixed cultures. Pol. J. Environ, Stud., 21(5), 1399-1403.

Toвih, J.E., Taiwo, S.S., Olowe, O.A., Olaosun, O.A. \& Adejumao, S.D. (2006): Clinical and microbiological profiles of ear infections in Osogbo, Nigeria. Trop Doct, 36(3), 165-166.

Travers, K. \& Barza, M. (2002): Morbidity of infections caused by antimicrobial-resistant bacteria. Clin. Infect Dis., 34(3), 131-134.

WALDERMAN, R.J. (1998): Epidemiological determinants of spread of causal agents of diarrheal disease. Lancet, 361 , 1761-1767.

Yismaw, G., Negeri, C. \& Kassu, A. (2006): A five-year antimicrobial resistance pattern observed in Shigella species isolated from stool samples in Gondar University Hospital, northwest Ethiopia. Ethiop. J. Health Dev., 20(3), 194-198. 